\title{
Effect of Lactobacillus salivarius on growth performance, diarrhea incidence, fecal bacterial population and intestinal morphology of suckling pigs challenged with $\mathrm{F}^{+}$enterotoxigenic Escherichia coli
}

\author{
Harutai Sayan ${ }^{1}$, Pornchalit Assavacheep ${ }^{2}$, Kris Angkanaporn ${ }^{3}$, and Anongnart Assavacheep ${ }^{1, *}$
}

\author{
* Corresponding Author: Anongnart Assavacheep \\ Tel: +66-2-218-9678, Fax: +66-2-251-2582, \\ E-mail: Anongnart.S@chula.ac.th \\ 'Department of Animal Husbandry, Faculty of \\ Veterinary Science, Chulalongkorn University, \\ Bangkok 10330, Thailand \\ 2 Department of Veterinary Medicine, Faculty of \\ Veterinary Science, Chulalongkorn University, \\ Bangkok 10330, Thailand \\ ${ }^{3}$ Department of Veterinary Physiology, Faculty of \\ Veterinary Science, Chulalongkorn University, \\ Bangkok 10330, Thailand \\ ORCID \\ Harutai Sayan \\ https://orcid.org/0000-0003-0762-2075 \\ Pornchalit Assavacheep \\ https://orcid.org/0000-0002-2236-0336 \\ Kris Angkanaporn \\ https://orcid.org/0000-0001-9195-136X \\ Anongnart Assavacheep \\ https://orcid.org/0000-0002-6305-6736
}

Submitted Oct 10, 2017; Revised Dec 15, 2017; Accepted Mar 13, 2018
Objective: Gut health improvements were monitored with respect to growth performance, diarrhea incidence, fecal bacterial population and intestinal morphology of suckling pigs orally supplemented with live Lactobacillus salivarius (L. salivarius) oral suspensions and challenged with $\mathrm{F}^{+}$enterotoxigenic Escherichia coli (ETEC).

Methods: Two groups of newborn pigs from 18 multiparous sows were randomly designated as non-supplemented (control: $\mathrm{n}=114$ piglets) and $L$. salivarius supplemented groups (treatment: $\mathrm{n}=87$ piglets). Treatment pigs were orally administered with $2 \mathrm{~mL}$ of $10^{9}$ colony-forming unit $(\mathrm{CFU}) / \mathrm{mL}$ L. salivarius on days 1 to 3 , then they were orally administered with $5 \mathrm{~mL}$ of $10^{9} \mathrm{CFU} / \mathrm{mL}$ L. salivarius on days 4 to 10 , while those in control group received an equal amount of phosphate buffered saline solution. On day 24 (2 weeks post supplementation), one pig per replicate of both groups was orally administered with $10^{8} \mathrm{CFU} / \mathrm{mL} \mathrm{F} 4^{+}$ETEC, then they were euthanized on day 29 of experiment.

Results: Results revealed that pigs in treatment group had a statistically significant increase in average daily gain, body weight and weight gain, and tended to lower diarrhea throughout the study. Numbers of Lactobacillus population in feces of treatment pigs were higher than control pigs, especially on day 10 of study. Numbers of total bacteria in intestinal contents of control pigs were also increased, but not Coliform and Lactobacillus populations. Histological examination revealed statistically significant improvements of villous height and villous/crypt ratio of duodenum, proximal jejunum and distal jejunum parts of treatment pigs compared with controls. Duodenal $\mathrm{pH}$ of treatment group was significantly decreased.

Conclusion: Oral supplementation of live L. salivarius during the first 10 days of suckling pig promoted growth performance and gut health, reduced diarrhea incidence, increased fecal Lactobacillus populations and improved intestinal morphology.

Keywords: Enterotoxigenic Escherichia coli F4; Fecal Bacterial Population; Growth Performance; Intestinal Morphology; Lactobacillus salivarius; Suckling Pigs

\section{INTRODUCTION}

The first month of piglet life is the most critical period, because the immune system remains not fully competent. Newborn piglets are often infected with pathogenic bacteria transmitted from either sows or environment. Neonatal diarrhea of piglets is caused by enterotoxigenic Escherichia coli (ETEC) [1]. Severity of diarrhea can be up to 50\% in suckling pigs [2]. ETEC, especially fimbriae type 4 (F4) harboring strain is the most important bacterial pathogen during the first week of a pigs life. It causes severe watery diarrhea in newborn and also early weaned piglets. ETEC produces toxins including heat-stable enterotoxins (STa and 
$\mathrm{STb}$ ) and heat-labile enterotoxin (LT), which potentially inhibit the absorption of sodium and chloride ions from intestinal lumen and stimulate the secretion of intestinal fluid, resulting in water and electrolyte losses [3]. In general, antimicrobials are often used to treat the bacterial infection. Among the side effects of intensive antimicrobial usage to fight the pathogen; some adverse effects such as destroying the beneficial bacteria, residues in pork products, and possibly increasing antimicrobial resistance are cause concern [4]. Therefore, non-antibiotic substances are considered to be alternatives to avoid such deleterious effect. Nowadays, prebiotics, probiotics, organic acids, enzymes, herbs and other non-antibiotic products/compound are widely used in pig production.

Supplementation of probiotics (live microorganisms) is aimed to balance intestinal microflora, increase number of beneficial microorganisms and stimulate the pig immune system. In previous study, improvement of growth performance of probiotic supplemented pigs was demonstrated [5]. Lactobacillus salivarius (L. salivarius) is a member of gram-positive bacteria. It grows in anaerobic and acidic conditions, with the optimal $\mathrm{pH}$ being 5.5 to 6.5 [6]. L. salivarius produces lactic acid and short chain fatty acids from glucose fermentation in glycolysis pathway [7]. It also inhibits bacterial pathogen growth [8]. From this circumstance, use of L. salivarius as probiotic would appear to offer benefits for pig gut health. In the present study, an isolate of $L$. salivarius was obtained from a Thai commercial pig producing farm and considered as a potential candidate for use as probiotic. The objective of this experiment was to investigate the effects of $L$. salivarius on growth performance, diarrhea incidence, fecal and intestinal microorganism, and intestinal morphology of suckling pigs challenged with Escherichia coli (E. coli) F4.

\section{MATERIALS AND METHODS}

\section{Animal care}

This research investigation was conducted according to protocol approved by Chulalongkorn University Animal Care and Use Committee (Animal Use Protocol No.1431071).

\section{Experimental designs}

The experiment was performed at a commercial pig producing farm in Ratchaburi Province, Western part of Thailand. Standard farm management system was routinely performed by farm staff. Eighteen crossbred newborn pig (Duroc $\times$ Yorkshire $\times$ Landrace) litters were randomly divided into two groups (10 to 12 piglets/L): control group $(\mathrm{n}=114$ piglets, from 10 sows) and treatment group ( $\mathrm{n}=87$ piglets, from 8 sows). No cross-fostering was implemented in any experiment litters throughout the study. Each litter was individually housed in stainless steel pens with plastic-coated and concrete expanded floors. Piglets had free access to sow milk and water.
During the first 3 days of study, each piglet in treatment group was orally administered with $2 \mathrm{~mL}$ of L. salivarius $10^{9}$ colony-forming unit $(\mathrm{CFU}) / \mathrm{mL} / \mathrm{d}$. An increased volume of inoculum up to $5 \mathrm{~mL}$ of $L$. salivarius $10^{9} \mathrm{CFU} / \mathrm{mL} / \mathrm{d}$ was orally administered during days 4 to 10 . All control piglets were given the equal volumes of phosphate buffered saline solution (PBS). On days 10 to 29 of experiment, creep feed was offered $a d l i-$ bitum.

In challenge experiment, one piglet per litter from each group was randomly chosen (10 control and 8 treatment pigs), and orally administered with $5 \mathrm{~mL}$ of $10^{8} \mathrm{CFU} / \mathrm{mL}$ E. coli $\mathrm{F} 4$. Clinical observations of diarrhea sign were monitored and recorded daily. On days 5, 10, 17, and 24, fecal samples from all pigs were collected by rectal swab technique (sterile cotton swab) and stored at $4^{\circ} \mathrm{C}$ until analysis within each collection day. On day 29, all challenged pigs were humanely euthanized with sodium pentobarbital $50 \mathrm{mg} / \mathrm{kg}$ intravenous injection. Standard necropsy procedure was carefully performed to inspect pathological lesions. Samples and luminal contents were collected from duodenum, proximal jejunum, distal jejunum, and ileum for histology and bacterial cultivation, respectively. The $\mathrm{pH}$ of intestinal contents from such locations was measured using digital $\mathrm{pH}$ meter.

Five hundred grams of creep feed were randomly collected for proximate analysis as follows: dry matter and moisture were analyzed with air oven method, ash (muffle furnace method), crude protein (Kjeldahl method), crude fat (Soxhlet method), crude fiber, calcium and phosphorus (UV-VIS spectrophotometer) and gross energy analyzed with bomb calorimeter [9].

\section{Microbiological laboratory}

Preparation of L. salivarius and E. coli: L. salivarius was freshly prepared by culture on DE MAN, ROGOSA and SHARPE (MRS agar, Lab M Ltd, Heywood, England). Colonies of $L$. salivarius were inoculated to $5 \mathrm{~mL}$ MRS broth ( $\mathrm{pH} 5.5$ ) and incubated at $37^{\circ} \mathrm{C}$ in carbon dioxide incubator for 24 hours, transferred into a total volume $1 \mathrm{~L}$, and incubated at $37^{\circ} \mathrm{C}$ for 24 hours in carbon dioxide incubator. After that, L. salivarius in MRS broth was adjusted to $10^{9} \mathrm{CFU} / \mathrm{mL}$.

Stock of E. coli F4 strain was cultured on MacConkey agar and incubated at $37^{\circ} \mathrm{C}$ for 18 hours. Colonies of overnight grown E. coli $\mathrm{F} 4$ were then transferred to $100 \mathrm{~mL}$ tryptic soy broth (TSB, Merck Co., Ltd, Darmstadt, Germany) and incubated at $37^{\circ} \mathrm{C}$ for 24 hours and a count made of the number of colonies. Then, E. coli $\mathrm{F} 4$ in TSB was adjusted to $10^{8} \mathrm{CFU} /$ $\mathrm{mL}$ using $0.5 \mathrm{McF}$ arland as standard and then cultivated on plate count agar (PCA, Merck Co., Ltd, Germany) for determination of bacterial concentration.

Laboratory analyses for determination of fecal/intestinal bacterial population: One gram of samples (fresh feces or intestinal contents) was transferred into $9 \mathrm{~mL}$ of sterile peptone 
PBS (0.1\%) and mixed thoroughly. One mL of fecal suspension was transferred into another tube containing $9 \mathrm{~mL}$ sterile PBS. A serial of 10 -fold dilution was made to $10^{-3}$ to $10^{-8}$. Then, one $\mathrm{mL}$ of each dilution was duplicated and transferred to sterile agar plate and topped up with freshly made sterile agar and spread plate. The culture media for total bacteria, coliform and lactobacillus counts, including culture conditions were PCA incubated at $37^{\circ} \mathrm{C}$ for 48 hours; violet red bile agar (VRB, Merck Co., Ltd, Germany) incubated at $37^{\circ} \mathrm{C}$ for 24 hours; and MRS agar incubated in carbon dioxide incubator at $37^{\circ} \mathrm{C}$ for 72 hours, respectively. The dilution plates with colony numbers range of 15 to 150 colonies were recorded [10]. Finally, an average of duplicate plates was calculated and expressed as $\log _{10}$ $\mathrm{CFU} / \mathrm{mL}$.

\section{Clinical evaluations}

Diarrhea incidence and fecal score: Number of pigs showing clinical signs of diarrhea and consistency of feces were daily monitored by the same investigator. Fecal consistency representing severity of diarrhea was evaluated and categorized as 4 scores: score 0 as normal solid feces; score las semi-solid feces; score 2 as water feces with some solid material; and score 3 as profuse watery feces with little or no solid fecal content [11]. Fecal scores and diarrhea incidence (DI) of each group were calculated according to the formula below $[12,13]$.

$$
\begin{gathered}
\text { Fecal scores }=\left(\begin{array}{c}
\text { Sum of the diarrhea score over the period }) \\
/(\text { experiment days })
\end{array}\right. \\
\text { DI }(\%)=\left(\begin{array}{l}
\text { Numbers of pigs with diarrhea of each group } \\
\times \text { diarrhea days } \times 100) \\
/(\text { Total pigs in group } \times \text { experiment days })
\end{array}\right.
\end{gathered}
$$

\section{Pig performance}

All animals were individual weighed on days 1, 10, 17, 24, and 29. This was used to calculate average body weight, average daily gain (ADG) and weight gain.

\section{Intestinal morphology}

Intestinal tissues from middle part of duodenum, proximal jejunum, distal jejunum, and ileum were cut approximately $2 \mathrm{~cm}$ length. The intestinal segment was fixed with pins on a foam and kept in $10 \%$ formalin buffered solution. The sample was embedded in paraffin and cut with microtome and stained with hematoxylin and eosin staining (H\&E) [14]. Five villi and crypt areas were systemically chosen per sample for villous height and crypt depth measurement. Villous height was measured from tip of villi to villi-crypt junction. Crypt depth was measured from base of villi to the lowest point of crypt. Villous height and crypt depth were measured using an Isolution lite software version 10.1.

\section{Statistical analyses}

All data were expressed as mean \pm standard error of the mean. The statistical analyses were analyzed using unpaired $t$-test for growth performance, diarrhea incidence, fecal and intestinal bacterial counts. The weight of piglets before and after challenged with $E$. coli $\mathrm{F} 4$ was analyzed by paired t-test. Differences of $\mathrm{p}<0.05$ were considered as statistical significant difference using MIXED procedure of SAS 2002 [15].

\section{RESULTS}

Oral supplementation of live L. salivarius suspension in suckling pigs was investigated following an E. coli F4 challenge, with respect to growth performance, diarrhea incidence, fecal bacterial population, and intestinal morphology. The pig production and health situations during experiment remained within an acceptable level of Thai farm standard. Porcine Reproductive and Respiratory Syndrome (PRRS) antibody was detected in suckling period from sows and remained positive in nursery period until 11 to 12 weeks of age. No unstable PRRS was identified in sow and nursery population. The result of feed analysis is shown in Table 1.

Overall effects of $L$. salivarius supplementation on pig growth performances were determined. In Table 2, average pig weight of both groups was $1.59 \mathrm{~kg}$ at the beginning of experiment. On days 10, 17, and 24 pigs in treatment group appeared to be heavier than control, but the only statistically significant difference was found on day 24. During days 1 to 24 , weight gain of treatment group was higher than control group for $0.68 \mathrm{~kg}$ ( 4.58 and $3.90 \mathrm{~kg} / \mathrm{pig})(\mathrm{p}<0.05)$. Also, the ADG of treatment group was better than control for $28.62 \mathrm{~g} / \mathrm{d}$ $(191.20$ and $162.58 \mathrm{~g} / \mathrm{d})$ during the same period $(\mathrm{p}<0.05)$. Following E. coli $\mathrm{F} 4$ challenge, weight loss of control piglets was greater than in the treatment group for $0.12 \mathrm{~kg} / \mathrm{pig}(0.45$ and $0.33 \mathrm{~kg}$, respectively) $(\mathrm{p}<0.01)$.

Improvement of pig performance is theoretically linked to pig gut health. Therefore, clinical data of pig diarrhea was collected to evaluate impact of $L$. salivarius supplementation on pig gut health. Diarrhea incidence, number of diarrhea days

Table 1. The nutrients composition analysis of creep feed used in this study

\begin{tabular}{lc}
\hline Nutrients & $\%$ \\
\hline Gross energy ${ }^{1)}(\mathrm{kJ} / \mathrm{kg})$ & $16,616.15$ \\
Dry matter & 92.46 \\
Moisture & 7.54 \\
Protein & 19.89 \\
Crude fat & 5.50 \\
Crude fiber & 0.88 \\
Ash & 6.33 \\
Calcium & 0.73 \\
Phosphorus & 0.50 \\
${ }^{1)}$ Gross energy was analyzed using Bomb Calorimeter.
\end{tabular}


Table 2. Effect of Lactobacillus salivarius on pig weight $(\mathrm{kg})$ of piglets before and after being challenged with Escherichia coli F4

\begin{tabular}{lcccc}
\hline Items & Control & L. salivarius & SEM & p-value \\
\hline Weight on day 1 & 1.59 & 1.59 & 0.01 & 0.911 \\
Weight on day 10 & 3.17 & 3.29 & 0.08 & 0.511 \\
Weight on day 17 & 4.39 & 4.74 & 0.13 & 0.203 \\
Weight on day 24 & 5.49 & $6.18^{*}$ & 0.16 & 0.033 \\
ADG (g/d) & 162.58 & $191.20^{*}$ & 6.85 & 0.033 \\
Weight gain & 3.90 & $4.58^{*}$ & 0.16 & 0.033 \\
Before challenged (day 24) & $6.09^{\mathrm{a}}$ & 6.08 & - & - \\
After challenged (day 29) & $5.64^{\mathrm{b}}$ & 5.75 & - & - \\
SEM & 0.17 & 0.23 & - & - \\
p-value & 0.005 & 0.057 & - & - \\
\hline
\end{tabular}

SEM, standard error of the mean; $A D G$, average daily gain.

* Means in the same row are significant different $(p<0.05)$.

${ }^{a, b}$ Means in the same column (pair T-test) are significant different $(p<0.01)$.

and fecal scores of treatment group were less severe than control group. Treatment group had overall average diarrhea incidence $9.16 \%$, whereas control group was $13.26 \%$. Similar circumstances to diarrhea score, treatment group appeared to be lower than control group during pre- and post-inoculation periods, but did not show a statistical significant difference. Only average diarrhea pig number between two groups (4.70 and $6.80 \mathrm{pigs} / \mathrm{d}$ ) was statistically significant different during pre-inoculation period. Furthermore, fecal scores of piglets in treatment group seemed to decrease compared with control group (Table 3).

Following improvement of clinical data in L. salivarius supplementation, gut environmental conditions were determined to explain whether $L$. salivarius supplementation could modulate intestinal $\mathrm{pH}$, microbial population and gut morphology and subsequently supported pig gut health or not. The intestinal content $\mathrm{pH}$ was measured regarding to various parts of intestine. A pH range of 6.08 to 6.88 was observable. Intestinal content $\mathrm{pH}$ values of treatment and control groups were not dissimilar in proximal and distal jejunum or ileum. Only average $\mathrm{pH}$ of duodenal content in treatment group (6.08) was statistically significantly reduced, compared to control group
(6.45) (Table 4).

Effect of L. salivarius supplementation on microbial population of pig gut was further investigated. Overall fecal bacterial population of treatment groups tended to be higher than control, including coliform bacterial and Lactobacillus species (Table 5). The average total bacteria in feces of con-

Table 4. Effect of Lactobacillus salivarius on $\mathrm{pH}$ of intestinal contents of piglets challenged with Escherichia coli F4

\begin{tabular}{lcccc}
\hline Items & Control & L. salivarius & SEM & p-value \\
\hline Duodenum & 6.45 & $6.08^{*}$ & 0.07 & 0.012 \\
Proximal Jejunum & 6.23 & 6.30 & 0.10 & 0.740 \\
Distal Jejunum & 6.79 & 6.71 & 0.07 & 0.622 \\
Ileum & 6.88 & 6.84 & 0.04 & 0.669 \\
\hline
\end{tabular}

SEM, standard error of the mean.

${ }^{*}$ Means in the same row are significant different $(p<0.05)$.

Table 5. Effect of Lactobacillus salivarius on fecal bacterial population of piglets challenged with Escherichia coli F4 (Log10 cfu/mL)

\begin{tabular}{lcccc}
\hline Items & Control & L. salivarius & SEM & p-value \\
\hline Total bacteria & & & & \\
Day 5 & 8.70 & 9.01 & 0.10 & 0.155 \\
Day 10 & 8.64 & 8.93 & 0.10 & 0.177 \\
Day 17 & 8.26 & 8.50 & 0.14 & 0.423 \\
Day 24 & 8.05 & 8.39 & 0.14 & 0.306 \\
Average & 8.41 & 8.71 & - & - \\
Total coliform & & & & \\
Day 5 & 8.16 & 8.23 & 0.10 & 0.724 \\
Day 10 & 8.07 & 8.15 & 0.16 & 0.838 \\
Day 17 & 7.62 & 8.03 & 0.15 & 0.202 \\
Day 24 & 7.63 & 7.63 & 0.14 & 0.988 \\
Average & 7.87 & 8.01 & & \\
Total lactobacillus & & & & \\
Day 5 & 7.83 & 8.07 & 0.14 & 0.420 \\
Day 10 & 7.04 & $8.51^{*}$ & 0.17 & 0.001 \\
Day 17 & 7.73 & 8.17 & 0.14 & 0.118 \\
Day 24 & 7.67 & 8.23 & 0.15 & 0.078 \\
Average & 7.56 & 8.25 & - & - \\
\hline
\end{tabular}

SEM, standard error of the mean.

${ }^{*}$ Means in the same row are significant different $(p<0.01)$.

Table 3. Effect of Lactobacillus salivarius on diarrhea incidence of piglets challenged with Escherichia coli F4

\begin{tabular}{|c|c|c|c|c|}
\hline Items & Control & L. salivarius & SEM & p-value \\
\hline Number of piglets ( $n$ ) & 114 & 87 & - & - \\
\hline Diarrhea incidence (\%) & 13.26 & 9.16 & 1.30 & 0.122 \\
\hline Fecal score ${ }^{1)}$ & 0.50 & 0.39 & 0.04 & 0.194 \\
\hline Fecal score $e^{2)}$ & 1.40 & 1.05 & 0.09 & 0.065 \\
\hline Average number of diarrhea day (days 1 to 24) & 4.80 & 4.25 & 0.245 & 0.278 \\
\hline Average number of diarrhea day (days 25 to 29 ) & 3.10 & 2.80 & 0.198 & 0.588 \\
\hline Average number of piglets diarrhea on days 1 to 24 & 6.80 & $4.70^{*}$ & 0.488 & 0.033 \\
\hline
\end{tabular}

SEM, standard error of the mean.

1) Fecal score of piglets before challenge (experimental days 1-24).

2) Fecal score of piglets after challenge (experimental days 25-29).

* Means in the same row are significant different $(p<0.05)$. 
trol and treatment groups was $\log _{10} 8.41$ and $8.71 \mathrm{CFU} / \mathrm{mL}$, respectively. The average total coliform bacteria was $\log _{10} 7.87$ and $8.01 \mathrm{CFU} / \mathrm{mL}$, whereas average total Lactobacillus species was $\log _{10} 7.56$ and $8.25 \mathrm{CFU} / \mathrm{mL}$, respectively. Only on day 10 of experiment, total fecal lactobacillus count of treatment group was increased compared with the control group $(\mathrm{p}<0.01)$. Moreover, the ratio of total lactobacillus count and total bacteria count ratio (TLC:TBC ratio), total coliform and total bacterial count (TCC:TBC) and the total lactobacillus count and total coliform count ratio (TLC:TCC ratio), were not significantly different (data not shown). Challenge experiment using E. coli $\mathrm{F} 4$ strain was further conducted by examination of bacterial populations. Piglets in treatment group had a higher average total bacterial count in duodenum, proximal jejunum, distal jejunum and ileum $\left(\log _{10} 6.32,6.99,7.69\right.$, and $7.79 \mathrm{CFU} / \mathrm{mL})$ compared with control group $\left(\log _{10} 5.13,5.69\right.$, 6.51, and 6.23 CFU/mL) $(\mathrm{p}<0.05)$ (Table 6). When focused on each location, total bacteria in treatment group was significantly higher than control $(\mathrm{p}<0.05)$, but total coliform, total lactobacillus counts and TLC:TBC, TCC:TBC, and TLC:TCC ratios were not different (data not shown).

Intestinal morphology of piglets was evaluated following challenge. Treatment group had better villi height in duodenum, proximal jejunum, and distal jejunum parts, compared to those of control group (Figure 1, $\mathrm{p}<0.01$ ). The crypt depth did not differ between groups. However, the villous height and crypt depth ratio (VH:CD) in duodenum in treatment group was significantly increased $(\mathrm{p}<0.05)($ Table 7$)$.

\section{DISCUSSION}

This study was conducted to investigate the effects of oral live

Table 6. Effect of Lactobacillus salivarius on intestinal bacterial population of piglets challenged with Escherichia coli F4 (Log10 cfu/mL)

\begin{tabular}{lcccc}
\hline Items & Control & L. salivarius & SEM & p-value \\
\hline Total bacteria & & & & \\
$\quad$ Duodenum & 5.13 & $6.32^{*}$ & 0.28 & 0.032 \\
$\quad$ Proximal Jejunum & 5.69 & $6.99^{*}$ & 0.29 & 0.021 \\
$\quad$ Distal Jejunum & 6.51 & $7.69^{*}$ & 0.27 & 0.027 \\
Ileum & 6.23 & $7.79^{*}$ & 0.33 & 0.014 \\
Total coliform & & & & \\
$\quad$ Duodenum & 5.14 & 5.95 & 0.51 & 0.452 \\
$\quad$ Proximal Jejunum & 5.68 & 6.71 & 0.60 & 0.374 \\
$\quad$ Distal Jejunum & 5.31 & 6.16 & 0.52 & 0.434 \\
$\quad$ Ileum & 5.02 & 6.06 & 0.45 & 0.268 \\
Total lactobacillus & & & & \\
$\quad$ Duodenum & 5.41 & 6.73 & 0.41 & 0.116 \\
$\quad$ Proximal Jejunum & 5.79 & 6.93 & 0.39 & 0.124 \\
$\quad$ Distal Jejunum & 6.43 & 6.88 & 0.34 & 0.532 \\
$\quad$ lleum & 5.54 & 6.71 & 0.40 & 0.149 \\
\hline SEM, standard error of the mean. & & & \\
* Means in the same row are significant different $(p<0.05)$. &
\end{tabular}
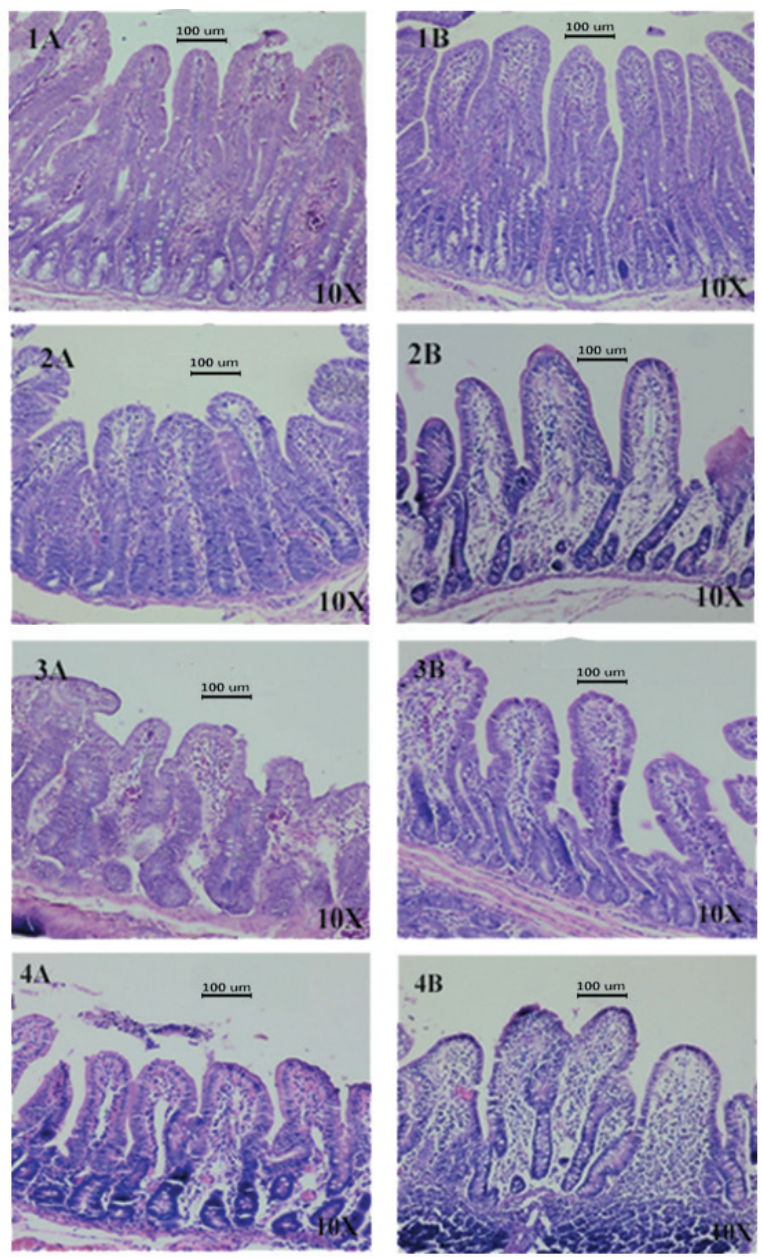

Figure 1. Effect of Lactobacillus salivarius (L. salivarius) on intestinal microscopic morphology (H\&E staining) of piglets challenged with Escherichia coli F4. Villus height and crypt depth ( $\mu \mathrm{m})$ were measured using an Isolution lite software version 10.1. (A) control group, (B) L. salivarius group, (1) duodenum, (2) proximal jejunum, (3) distal jejunum, and (4) ileum.

L. salivarius suspension supplementation in suckling pigs following with E. coli $\mathrm{F} 4$ challenged, with respect to growth performance, diarrhea incidence, fecal bacterial population, and intestinal morphology. Overall effects revealed that $L$. salivarius supplementation improved ADG and weight gain of piglets. This is similar to previous studies that reported $L$. salivarius B1 [16] or L. brevis 1E-1 [17] supplementation increased daily weight gain of piglets. This advantageous effect of $L$. salivarius supplementation on growth performance may relate to improve villous height of piglets as demonstrated in this study. L. salivarius may also modulate intestinal environment and/or growth of intestinal microflora, resulting in limitation of diarrhea [18]. Other previous studies suggested that Lactobacillus species supplementation may stimulate the secretion of mucus, then promote growth of intestinal microflora $[4,19]$. In general, probiotics are intended to maintain the intestinal ecosystem and improve animal health [7]. Probiotic bacteria produce several anti-microorganism substances such as bac- 
Table 7. Effect of Lactobacillus salivarius on intestinal morphology of piglets challenged with Escherichia coli F4

\begin{tabular}{|c|c|c|c|c|}
\hline Items & Control & L. salivarius & SEM & p-value \\
\hline \multicolumn{5}{|l|}{ Villous height $(\mathrm{VH}, \mu \mathrm{m})$} \\
\hline Duodenum & 251.13 & $297.65^{* *}$ & 9.169 & 0.007 \\
\hline Proximal Jejunum & 253.85 & $290.41^{* *}$ & 6.871 & 0.004 \\
\hline Distal Jejunum & 258.36 & $281.82^{* *}$ & 4.416 & 0.004 \\
\hline Ileum & 158.01 & 175.10 & 6.377 & 0.199 \\
\hline \multicolumn{5}{|l|}{ Crypt depth $(C D, \mu m)$} \\
\hline Duodenum & 135.85 & 142.83 & 5.059 & 0.509 \\
\hline Proximal Jejunum & 123.53 & 132.16 & 3.296 & 0.254 \\
\hline Distal Jejunum & 129.83 & 130.68 & 3.353 & 0.904 \\
\hline Ileum & 107.55 & 105.88 & 4.054 & 0.849 \\
\hline \multicolumn{5}{|c|}{ Villi height:crypt depth ratio (VH:CD ratio) } \\
\hline Duodenum & 1.91 & $2.12^{*}$ & 0.055 & 0.048 \\
\hline Proximal Jejunum & 2.11 & 2.26 & 0.046 & 0.116 \\
\hline Distal Jejunum & 2.02 & 2.25 & 0.064 & 0.068 \\
\hline Ileum & 1.48 & 1.75 & 0.075 & 0.077 \\
\hline
\end{tabular}

teriocin, hydrogen peroxide, carbon dioxide, and acetic acid [20], which support gut health. For example, bacteriocin allows inhibition of peptidoglycan of pathogenic bacteria and interference the function of cell membranes, resulting in inhibition of bacteria pathogens [21]. Enhancement of epithelial barrier [22], and concomitant inhibition of pathogen adhesion [23] by $L$. salivarius may also prevent intestinal damage, thus gut health and growth performances are increased [20]. However, this study did not investigate such mentioned effects.

Body weight loss is considered as a deleterious consequence following challenge. This is due to diarrhea following E. coli $\mathrm{F} 4$ exposure. ETEC, a common cause of diarrhea in newborn piglets [5], usually adheres to epithelium in duodenum, jejunum, and ileum. The toxins produced by E. coli F4 causes increase of $\mathrm{Cl}^{-}$secretion from crypt cells and impair of $\mathrm{Na}^{+}$and $\mathrm{Cl}^{-}$absorption by villus cells. Excess amount of electrolytes in intestinal lumen causes water lose and subsequent diarrhea [5]. In the present study, treatment group had a benefit of reduced diarrhea severity. This may be because $L$. salivarius produce lactic acid and other organic acids, which destroy electrochemical proton gradient of pathogenic cells. Therefore, pathogenic bacteria are degenerated $[12,20]$.

Earlier studies suggest that $L$. salivarius supplementation increases number of total Lactobacillus species in intestines, adheres to intestinal wall, and promotes excretion of pathogenic bacteria in feces $[24,25]$. Therefore, the present study was designed to supplement $L$. salivarius to newborn piglets for a consecutive 10-day period; this might be possible on farm using $L$. salivarius in form of oral suspension. We anticipated the modulation of $L$. salivarius in the pig gut and might prevent or reduce of diarrhea following $E$. coli challenge.
As expected, numbers of intestinal Lactobacillus species were only enhanced during period of supplementation. This signifies that $L$. salivarius may not last in intestine for long period. Therefore, a longer supplementation to producea higher Lactobacillus population may be an option for better outcome. Another concern in the present study was that total bacterial population in L. salivarius supplemented group increased and differed from control, whereas total lactobacillus and the total coliform bacteria did not differ between groups. Similar study [26] reported that Lactobacilli supplementation increased the number of total bacteria in jejunum. The explanation may be due to a limited period of $L$. salivarius supplementation, causing no prolonged growth of Lactobacillus in gut, and perhaps, due to the modulation of other bacterial communities in pig gut, resulting in higher total bacteria.

Intestinal morphology is an important indicator for probiotic supplementation. Better villous height presumes an improvment in the absorptive ability of small intestine. Lactobacillus spp. can produce short chain fatty acids to stimulate epithelial cells and enterocytes, and increase the villous height [27]. In the present study, increase of villous height of L. salivarius supplemented group was similar to an earlier result [22] who reported that, piglets in L. plantarum CGMCC had enhanced villi height and $\mathrm{VH}: \mathrm{CD}$ ratio of duodenum and jejunum. Similar extent following supplementation with $\mathrm{Lac}$ tobacilli was also revealed [28].

In conclusion, live $L$. salivarius oral supplementation during the first 10 days of suckling pig promoted growth performance and gut health, lessen diarrhea incidence and severity, and periodical enhanced fecal Lactobacillus populations, and improved intestinal morphology.

\section{CONFLICT OF INTEREST}

We certify that there is no conflict of interest with any financial organization regarding the material discussed in the manuscript.

\section{ACKNOWLEDGMENTS}

This study was supported, in part, by the 90th Anniversary of Chulalongkorn University Fund (Ratchadaphiseksomphot Endowment Fund), Chulalongkorn University, Thailand.

\section{REFERENCES}

1. Chan G, Farzan A, DeLay J, et al. A retrospective study on the etiological diagnoses of diarrhea in neonatal piglets in Ontario, Canada, between 2001 and 2010. Can J Vet Res 2013;77:25460.

2. Begum S, Patra MK, Ngullie L, et al. Antimicrobial resistance pattern in swine colibacillosis under farm and field condition 
in Nagaland. Int J Livest Res 2014;4:81-8.

3. Chandler D, Mynott T. Bromelain protects piglets from diarrhoea caused by oral challenge with K88 positive enterotoxigenic Escherichia coli. Gut 1998;43:196-202.

4. Estienne M, Hartsock T, Harper A. Effects of antibiotics and probiotics on suckling pig and weaned pig performance. Intern J Appl Res Vet Med 2005;3:303-8.

5. Moxley RA, Duhamel GE. Comparative pathology of bacterial enteric disease of swine. Adv Exp Med Biol 1999;473:83-101.

6. Salih N, Hutari A, Gaseem W, et al. Maximization of growth and storage of locally isolated Lactobacillus salivarius subsp. Salivarius with high stability and functionality. In: Proceedings of Southern Biomedical Engineering 2009; 2009 May 15-17, Miami, FL, USA: Springer-Verlag Berlin heidelberg; 2009. p. 175-8.

7. Meng QW, Yan L, Ao X, et al. Influence of probiotics in different energy and nutrient density diets on growth performance, nutrient digestibility, meat quality, and blood characteristics in growing-finishing pigs. J Anim Sci 2010;88:3320-6.

8. Vasala A, Panula J, Neubauer P. Efficient lactic acid production from high salt containing dairy by-products by Lactobacillus salivarius ssp. salicinius with pre-treatment by proteolytic microorganisms. J Biotechnol 2005;117:421-31.

9. Latimer GW. AOAC International. Official methods of analysis of AOAC International. 19th ed. Gaithersburg, MD, USA: AOAC International; 2012.

10. Bacteriological analytical manual online [Internet]. Food and Drug Administration; 2001 [cited 2014 Mar 18]. Available from: https://www.epa.gov/sites/production/files/2015-07/ documents/fda-bam-appendix1.pdf

11. Robb EJ, Bryson WL, Chester ST, et al. Efficacy of ceftiofur sodium for the control of mortality in neonatal pigs orally inoculated with K88 (F4) enterotoxigenic Escherichia coli. J Swine Health Prod 2003;11:7-11.

12. Giang HH, Viet TQ, Ogle B, et al. Growth performance, digestibility, gut environment and health status in weaned piglets fed a diet supplemented with potentially probiotic complexes of lactic acid bacteria. Livest Sci 2010;129:95-103.

13. Liu P, Piao X, Thacker P, et al. Chito-oligosaccharide reduces diarrhea incidence and attenuates the immune response of weaned pigs challenged with K88. J Anim Sci 2010;88:3871-9.

14. Tsirtsikos P, Fegeros K, Kominakis A, et al. Modulation of intestinal mucin composition and mucosal morphology by dietary phytogenic inclusion level in broilers. Animal 2012;6: 1049-57.

15. SAS. SAS/SAT guide for personal computers. 9.00ed. Carry, NC, USA: SAS Inst., Inc.; 2002.
16. Zhang J, Deng J, Wang C, et al. Modulatory effects of Lactobacillus salivarius on intestinal mucosal immunity of piglets. Curr Microbiol 2011;62:1623-31.

17. Banach S, Rehberger T, Parrott T, et al. Influence of Lactobacillus brevis strain 1E-1 on the gastrointestinal microflora of preweaning and weaning pigs. In: American Society of Animal Science Meeting 2002; 2002 Mach 18-20; Iowa, USA.

18. Rondon AJ, OjitoY, Arteaga FG, et al. Probiotic effect of Lactobacillus salivaruis $\mathrm{C} 65$ on productive and health indicators of lactating piglets. Cuban J Agric Sci 2013;47:401-7.

19. Yu H, Wang A, Li X, et al. Effect of viable Lactobacillus fermentum on the growth performance, nutrient digestibility and immunity of weaned pigs. J Anim Feed Sci 2008;17:61-9.

20. Ammor S, Tauveron G, Dufour E, et al. Antibacterial activity of lactic acid bacteria against spoilage and pathogenic bacteria isolated from the same meat small-scale facility: 1 -Screening and characterization of the antibacterial compounds. Food Control 2006;17:454-61.

21. Huang C, Qiao S, Li D, et al. Effects of lactobacilli on the performance, diarrhea incidence, VFA concentration and gastrointestinal microbial flora of weaning pigs. Asian-Australas J Anim Sci 2004;17:401-9.

22. Yang KM, Jiang ZY, Zheng CT, et al. Effect of Lactobacillus plantarum on diarrhea and intestinal barrier function of young piglets challenged with enterotoxigenic Escherichia coli K88. J Anim Sci 2014;92:1496-503.

23. Miriam BB, Julio PD, Sergio MQ, et al. Probiotic mechanisms of action. Ann Nutr Metab 2012;61:160-74.

24. Lähteinen T, Malinen E, Koort JM, et al. Probiotic properties of Lactobacillus isolates originating from porcine intestine and feces. Anaerobe 2010;16:293-300.

25. Zhang L, Xu YQ, Liu HY, et al. Evaluation of Lactobacillus rhamnosus GG using an Escherichia coli K88 model of piglet diarrhoea: Effects on diarrhoea incidence, faecal microflora and immune responses. Vet Microbiol 2010;141:142-8.

26. Lähteinen T, Rinttilä T, Koort JM, et al. Effect of a multispecies lactobacillus formulation as a feeding supplement on the performance and immune function of piglets. Livest Sci 2015;180: 164-71.

27. Suo C, Yin Y, Wang X, et al. Effects of Lactobacillus plantarum ZJ316 on pig growth and pork quality. BMC Vet Res 2012;8:89.

28. Maria MR, Deise OS, Ernesto AT, et al. IgA production, coliforms analysis and intestinal mucosa IgA production, coliforms analysis and intestinal mucosa morphology of piglets that received probiotics with viable or morphology of piglets that received probiotics with viable or inactivated cells inactivated cells. Pesq Vet Bras 2007;27:241-5. 